\title{
SUSTAINABILITY IN THE CONTEMPORARY MARKET ECONOMY
}

\author{
Cristina BĂTUŞARU*, Alina RĂDOIU** \\ *"Nicolae Bălcescu" Land Forces Academy, Sibiu, Romania \\ **”Lucian Blaga" University of Sibiu, Romania \\ batusaru.cristina@gmail.com, alina.cotinescu@yahoo.com
}

\begin{abstract}
Over time, the market economy has undergone many changes caused by the processes underlying its operation, and have focused on the scarcity of resources, interdependencies between economic agents, intensified exchanges, technical and scientific progress and computerization of economic systems. Given the many variables that act and ensure the functionality of the contemporary market economy, it is particularly important that the interdependencies between them be addressed in terms of sustainability. This paper addresses sustainability as a condition for supporting sustainable economic development, starting from the main links that support economic growth, namely production and consumption. Sustainable economic growth must be accompanied by measures to optimize the processes that characterize production and consumption, aiming at reducing resource waste, maximizing the intrinsic value of waste from economic activity and ensuring an infrastructure that makes it possible to move from the linear economy to the circular economy. Starting from the current stage of the steps taken to ensure sustainable economic development, the paper presents the main challenges faced by supply and demand, representing shortcomings in ensuring the road to circularity.
\end{abstract}

Keywords: sustainability, sustainable development, market economy, production, consumption.

\section{Introduction}

The concept of sustainability is a widely debated topic in the literature, finding its relevance in all areas of activity, not just economic. In a world marked by dynamics and constantly changing, sustainability comes as a condition imposed on economic processes to support the process of permanent change in a balanced way, so that resource exploitation, investment orientation, directions of technological development, research - development innovation [1] and the adaptation of the institutional architecture and the legislative support to be in harmony and to ensure the premises of a sustainable development. The approach to economic sustainability considers the existence of a sustainable system defined as a socio-ecological process involving international and national legislation and ensuring the optimization of planning and supply, production and consumption, reorganization and revaluation of economic sectors, use of technology and adjustment individual lifestyles for the rational use of resources [2].

In order to ensure the premises of sustainability, it is particularly important that this concept be deepened at both microeconomic and macroeconomic level, assessing in time and space the interdependencies that are established 
among social and economic environmental organizations.

From a microeconomic perspective, ensuring sustainability and increasing the sustainable value of the company becomes convergent with the integrated concept of the circular economy that aims to extend the product life cycle, better resource management and promote competitive and innovative products to meet consumer needs.

\section{Measuring and assessing economic sustainability}

Medium and long-term competitiveness among European Community countries depends to a large extent on the ability of each state to continue and intensify structural reforms in order to ensure a competitive but sustainable economy.

The objectives of competitiveness and economic development transposed into many European strategies and policies on sustainability, also required a system for evaluating and monitoring these performances. One of the most complex tools for assessing the sustainability of European economies is the Economic Sustainability Index which is based on 6 indices for assessing European economies covering different areas of sustainability: deficits, national debt, growth, competitiveness, governance / corruption and future costs of aging.

The monitoring of this indicator is subject to the 17 objectives that the 2030 Agenda for Sustainable Development [3] has set out to pursue, in order to strengthen global efforts to achieve sustainable economic development. The analysis of the elements that make up the economic sustainability index allows the assessment of European states of their long-term economic sustainability and provides a reference point to understand the position of each country in the context of a rapid change of economic environment and the need to adapt to significant changes in economic policies.

\subsection{Consumption and production - tools for ensuring economic sustainability}

In this context of ensuring sustainability, the developments of the contemporary market economy are dependent and determined by the actions taken by consumers and producers. One of the main objectives of the 2030 Agenda Strategy is to ensure sustainable production and consumption patterns.

The analysis of the sustainability of the elements that ensure the achievement of this objective requires a comprehensive set of actions from businesses, policy makers, researchers and consumers that need to adapt to sustainable practices [4].

From this perspective, the main challenge is the sustainability of production and consumption processes that must integrate advanced technological capacity, efficient and rational use of resources and low global waste.

In order to understand the current state and the steps taken in this field at European and national level, an analysis of the main indicators that characterize the sustainability of production and consumption is required.

The optimization of production and consumption processes must take into account the impact on the environment. Sustainable patterns of production and consumption patterns aim at the efficient use of limited resources and reducing the pressure on natural capital elements by keeping the environment clean and healthy and protecting the needs of future generations. This implies an increase in the circularity of materials in the economy, which means a reduction in the extraction of resources and the amount of waste that ends up in landfills or is incinerated, as well as safe management of chemicals and a shift from heavy use of carbon carriers to sustainable production of energy from renewable sources.

Such an approach would not only reduce the pressures on the environment, but also 
offer major economic benefits, represented by the reduction of production costs.

\subsection{Key issues on the progress of ensuring economic sustainability in the European Community}

The approach to resource consumption must be viewed from both directions of the economic circuit: production and final consumption, and the main objective of optimizing these processes is to improve the efficiency of resource and energy use, so that economic systems thus developed produce more with the same volume of resource and energy inputs.

The success of the development of these sustainable economic systems is based on ensuring an infrastructure that allows for the highest possible recycling rate and low energy consumption.

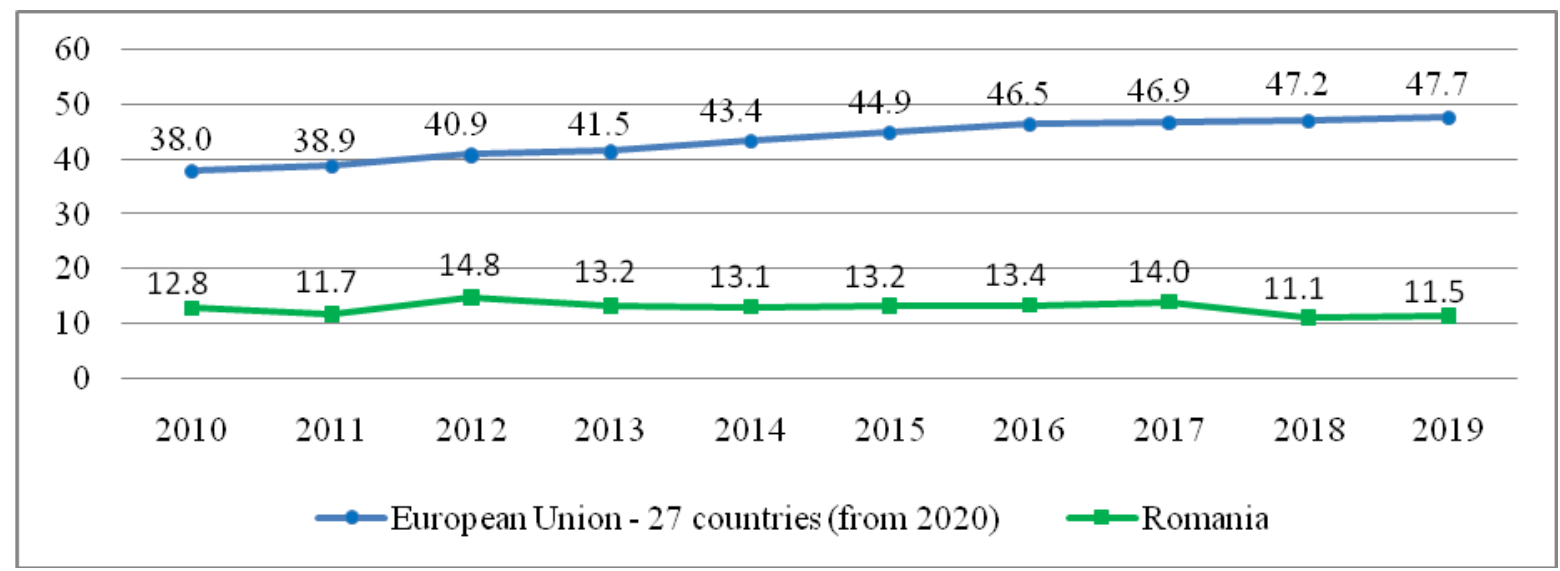

Figure 1: Recycling rate of municipal waste between 2010-2019

(as \% of total waste generated)

Source: made by the authors based on data taken from Eurostat https://ec.europa.eu/eurostat/web/products-statistical-books

This infrastructure is also supported by the legislative component [5], which has been integrated into the Action Plan on the implementation of the Circular Economy Package in 2018, and which provides for ambitious measures to recycle municipal and packaging waste. The target for municipal waste recycling, at community level, for 2030 is $60 \%$. Given the evolution of this indicator over the last decade, the target set is a bold one, but with a current and sustained implementation of sustainable production and consumption policy in EU countries, this goal can become a reality.

The municipal waste recycling rate registered by Romania does not shed much light on the performance of our country, highlighting certain syncopes regarding the implementation of waste recycling and recovery policies.

Once this infrastructure is secured, the emphasis shifts to the productivity of resources and energy thus exploited. European statistics [6] show that in the last decade the productivity of resources in the European Community has increased by $29.6 \%$ and energy productivity by $31.4 \%$. This can be justified by the economic growth that was based on the reduction in domestic material consumption and the reduction of available raw energy. 


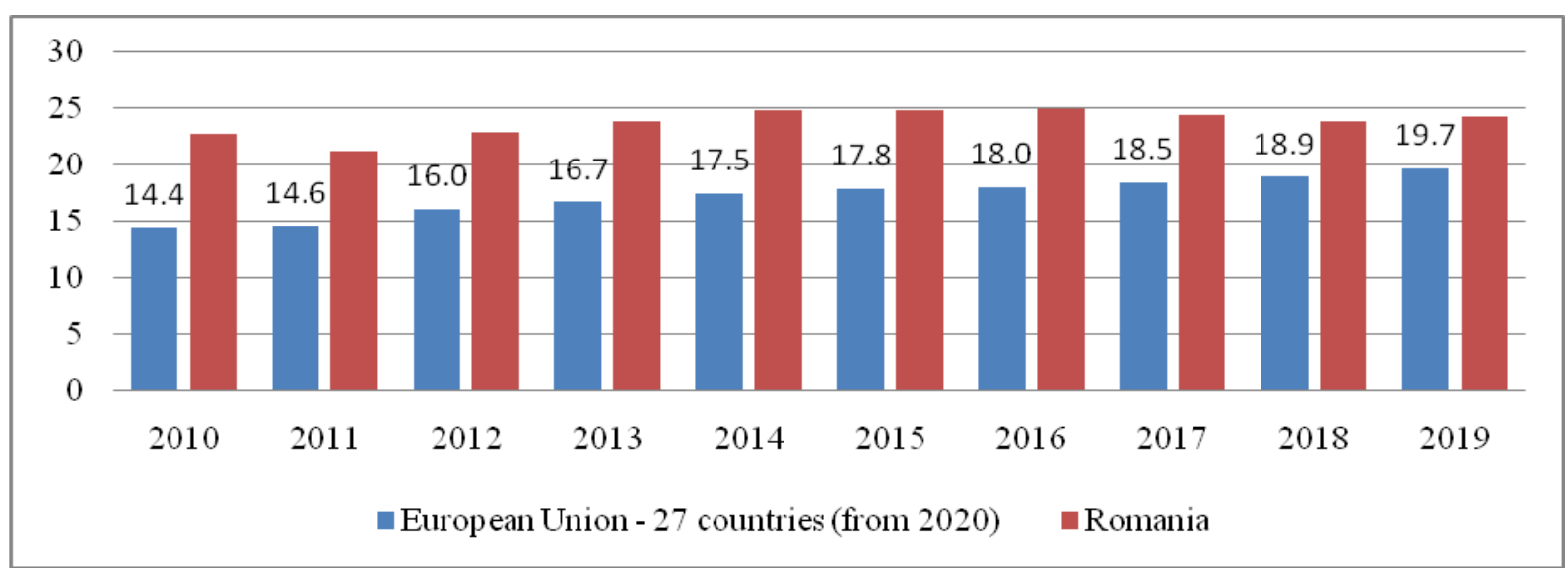

Figure 2: Share of renewable energy between 2010-2019

(as \% of gross final energy consumption)

Source: made by the authors based on data taken from Eurostat -

https://ec.europa.eu/eurostat/web/products-statistical-books

Ensuring innovation approaches at the level of manufacturing companies brings into question the importance that human resources have in modernizing productive systems and capitalizing on the tools available to extend the life cycle of products that the companies make. At European level, the share of employees in the business sector engaged in research and development has remained relatively low over the last decade, but there is a growing trend, which can be justified by the increased attention paid to human resources among the strategic objectives of community development, especially in the field of innovation.

However, at national level, our country is making modest progress in this area, the share of employees in the business environment who have responsibilities in the field of research and development being well below the European average.

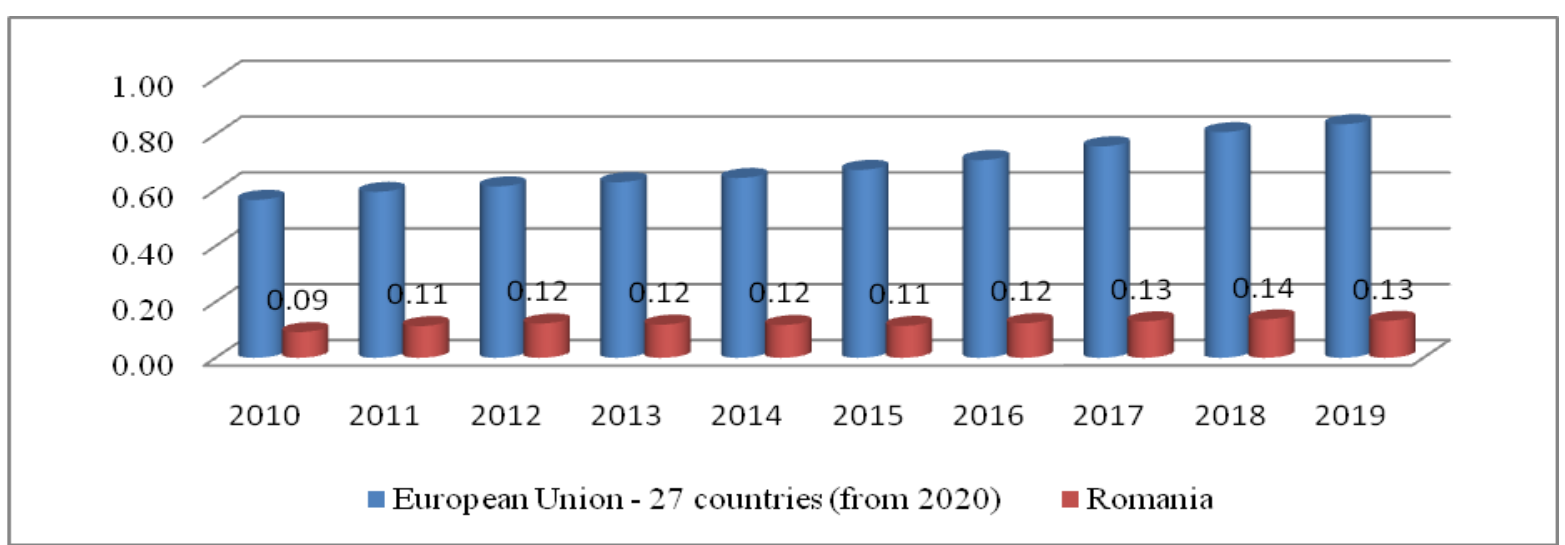

Figure 3: R\&D personnel in business enterprise sector

(as \% of the active population)

Source: made by the authors based on data taken from Eurostat -

https://ec.europa.eu/eurostat/web/products-statistical-books

\section{Ensuring the circularity of production and consumption}

Waste management resulting from economic activity is one of the most current issues of economic sustainability. Waste is considered a resource and not a residue, the economic value of which must be exploited to the fullest, avoiding waste. Keeping them in the economic circuit as much as possible, ensures the reduction of inputs and outputs of the resource flows, thus creating the premises of a circular economy. 
The evolutions regarding the utilization rate of the circular material in Romania, compared to the EU average, present an antagonistic trend. Although the share of reused materials in the volume of inputs in production processes represents small values, at Community level there is a slight upward trend in the period 2010-2019. But this evolution is not found in the case of Romania, where not only that the values of this indicator are particularly low, but they also register unfavorable developments in terms of the circularity rate.

The low values registered by this indicator are explained in the structural deficiencies regarding the implementation of the policies that support the circular economy. Firstly, a shortcoming is the fact that a significant share of the materials used are for the maintenance of buildings, infrastructure and other long-life goods, which does not make them immediately available for recycling. The second structural barrier that is a deficiency is the fact that a significant amount of material is used to obtain energy. For these materials, in particular for fossil fuels, closing the loop is hardly possible and the high share of these materials keeps the degree of circularity low [7].

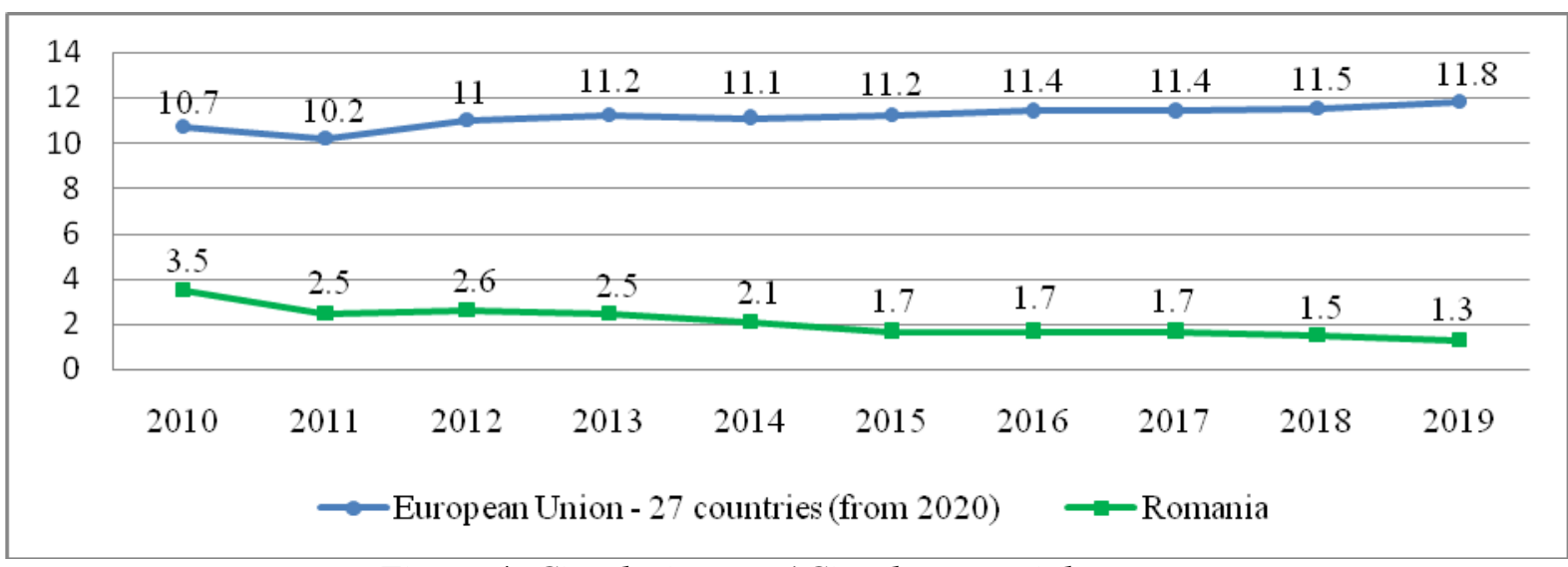

Figure 4: Circularity rate / Circular material use rate

(\% of material input)

Source: made by the authors based on data taken from Eurostat https://ec.europa.eu/eurostat/web/products-statistical-books

Ensuring the sustainability of the Community's economic environment is based on enhancing the green economy [8], which has the advantage of separating the negative impact on the environment from economic growth.

In this regard, greater attention should be paid to the environmental goods and services sector, which can help increase the market share of green, environmentally friendly technologies and provide many economic and social benefits in terms of increasing the added value created in the economy and adapting employment to market requirements.

Such an approach may target products and services that allow prevention, measurement, control, limiting, minimizing resource depletion and reducing environmental damage.

\section{Conclusions}

Ensuring sustainable economic development is directly dependent on how the complex processes of production and consumption manage to be optimized in such a way as to meet the objectives of the circular economy. The idea of tackling waste as a resource capable of being reintroduced into the economic circuit is the key to this mechanism of sustainability, but also the biggest challenge of contemporary economic systems. Human resources also play a particularly important role, as they 
are found on both sides of production and consumption. Orienting and attracting workers to key areas that support the process of innovation, research and development, and that participate in the production of technologies capable of prolonging the life cycle of products, should be a priority for economic policy makers. The importance of sustainable production and consumption policy, which includes a number of proposals to improve the environmental performance of products and increase the demand for more sustainable goods and production technologies, must therefore be taken into account.

\section{References List}

[1] Link, A. N., Siegel, D.S. Innovation, Entrepreneurship and Technological Change. New York: Oxford University Press; 2007.

[2] Dima (Girneata), A., \& Nedelcu, M.(2017). Competitiveness Analysis of the Romanian Economy. In C. Ignatescu, A. Sandu, \& T. Ciulei (eds.), Rethinking Social Action. Core Values in Practice (pp. 198-209). Suceava, Romania: LUMEN Proceedings https://doi.org/10.18662/lumproc.rsacvp2017.19

[3] European Commission (2019), Annual Sustainable Growth Strategy 2020, Available online:https://ec.europa.eu/info/publications/2020-european-semester-annualsustainable-growth-strategy_en;

[4] European Commission (2008), Sustainable Consumption and Production and Sustainable Industrial Policy Action Plan, COM(2008) 397 final, Brussels

[5] European Commission (2020), Communication from the Commission to the European Parliament, the Council, the European Economic and Social Committee and the Committee of the Regions - A new Circular Economy Action Plan: For a cleaner and more competitive Europe, COM(2020) 98 final, Brussels;

[6] European Commission, (2020). Sustainable development in the European Union. Monitoring report on progress towards the SDGs in an EU context, 2020 Edition, pp.221. Available from: https://ec.europa.eu/eurostat/web/products-statistical-books//ks-02-20-202;

[7] Haas, W., Krausmann, F., Wiedenhofer, D., Heinz, M. (2015), How Circular is the Global Economy?: An Assessment of Material Flows, Waste Production, and Recycling in the European Union and the World in 2005, in Journal of Industrial Ecology, October 2015, Vol.19(5), pp. 765-777;

[8] Done, I.; Chivu, L.; Andrei, J.; Matei, M., (2012). Using labor force and green investments in valuing the Romanian agriculture potential. J. Food Agric. Environ.2012, 10, pp.737-741. Available online: https://www.wflpublisher.com/Abstract/3502. 